\title{
Ativismo pedagógico e princípios da escola do trabalho nos primeiros tempos da educação soviética
}

\author{
MARISA BITTAR \\ Universidade Federal de São Carlos, \\ São Carlos, SP, Brasil
}

AMARILIO FERREIRA JR. Universidade Federal de São Carlos,

São Carlos, SP, Brasil

\section{RESUMO}

Examinamos neste artigo a influência do ativismo pedagógico nos primeiros tempos da educação soviética, de 1918 até o final da década de 1920. O estudo partiu da hipótese segundo a qual, nesse período, a pedagogia soviética teria mesclado tal influência com princípios marxistas da escola do trabalho. Quanto às fontes principais, baseamo-nos em discursos e artigos de três figuras importantes da revolução e educação no período: Anatoli Lounatcharski, Nadezja Konstantinovna Krupskaya e Vladimir Ilitch Lênin. Valemo-nos também de um texto pouco explorado de John Dewey sobre sua visita à Rússia Soviética, em 1928. O estudo concluiu que a presença do ativismo pedagógico foi típica do período de efervescência política da revolução, coincidindo com a campanha pela alfabetização e o início da construção do sistema nacional de escolas públicas, iniciando seu declínio na década de 1930, com a consolidação da revolução.

educação soviética; ativismo pedagógico; educação e trabalho. 


\section{PEDAGOGICAL ACTIVISM AND PRINCIPLES OF THE SCHOOL'S WORK IN THE EARLY DAYS OF SOVIET EDUCATION}

\section{ABSTRACT}

We examine in this paper the influence of pedagogical activism in the early days of soviet education, from 1918 to the late 1920s. The study started from the assumption that in this period the soviet pedagogy blended that influence with marxist principles of education and work. Regarding the main sources we have relied on speeches and articles on three important figures of the revolution and education in the period: Anatoli Lounatcharski, Nadezja Konstantinovna Krupskaya and Vladimir Ilitch Lênin. We also used an untapped text by John Dewey on his visit to Soviet Russia in 1928. The study concluded that the presence of activism teaching was typical of the period of political effervescence of the revolution, coinciding with the campaign for literacy and early construction of the national system of public schools and began to decline in the 1930s with the consolidation of the revolution.

\section{KEYWORDS}

soviet education; educational activism; education and work.

\section{ACTIVISMO PEDAGÓGICO Y PRINCIPIOS DE LA ESCUELA DEL TRABAJO EN LOS PRIMEROS TIEMPOS DE LA EDUCACIÓN SOVIÉTICA}

\section{RESUMEN}

Examinamos en este artículo la influencia del activismo pedagógico en los primeros tiempos de la educación soviética, desde 1918 hasta el final de la década de 1920. El estudio partió de la hipótesis según la cual, en este período, la pedagogía soviética habría mezclado tal influencia con principios marxistas de la escuela del trabajo. En cuanto a las principales fuentes, nos hemos basado en discursos y artículos de tres figuras importantes de la revolución y la educación en dicho período: Anatoli Lounatcharski, Nadezja Konstantínovna Krupskaya y Vladimir Ilitch Lênin. Hacemos uso también de un texto poco explorado de John Dewey sobre su visita a la Unión Soviética en 1928. El estudio llegó a la conclusión de que la presencia del activismo pedagógico fue típica del periodo de efervescencia política de la revolución, coincidiendo con la campaña de alfabetización y el inicio de la construcción del sistema nacional de escuelas públicas, comenzando a decaer en la década de 1930 con la consolidación de la revolución.

PALABRAS CLAVE

educación soviética; activismo pedagógico; educación y trabajo. 


\section{INTRODUÇÃO}

Em seu livro História da educação: da Antiguidade aos nossos dias, Mario Alighiero Manacorda deixa uma pista segundo a qual, no primeiro período da Revolução Bolchevique, o esforço educacional da Rússia contou com nomes que praticaram "a grande estação do ativismo pedagógico" (Manacorda, 1989, p. 313). Seguindo essa pista, nosso artigo focaliza a educação russa entre 1918 e o fim da década de 1920, buscando localizar em que pontos a concepção de John Dewey (1859-1952) se mesclou com os princípios da pedagogia marxista. Para isso, foram consultados artigos e discursos de três figuras importantes da revolução nesse período: Anatoli Lounatcharski (1875-1933), chefe do Comissariado do Povo Para a Instrução de 1917 a 1929; Nadezja Konstantinovna Krupskaya ${ }^{1}$ (1869-1939), pedagoga que desde o início da revolução dirigiu o comitê responsável pela educação extraescolar; e Vladimir Ilitch Lênin (1870-1924), líder dos bolcheviques na Revolução de 1917, que se dedicou pessoalmente à instauração do sistema escolar e à campanha pelo fim do analfabetismo na Rússia Soviética. Anteriormente a 1917, Lênin e Krupskaya, na condição de exilados políticos, viveram em países da Europa Ocidental e demonstraram interesse pelas suas experiências educacionais. Nikolay D. Korneychik, que foi pesquisador do Instituto Ylyanov de Pedagogia em Moscou, quando das comemorações dos noventa anos de nascimento de Nadezja Konstantinovna Krupskaya, escreveu o seguinte sobre as fontes teóricas que a educadora russa leu durante o exílio político:

Ela estudou um vasto número de fontes originais, as obras de K. Marx e F. Engels, e também quase todas as obras pedagógicas de Rousseau, Pestalozzi, R. Own, Fellenberg, Dewey, Kerchensteiner, Ferster e muitos outros. Além de trabalhos teóricos, ela se baseou também em artigos jornalísticos, obras literárias, material epistolar, memórias de educadores. (Korneychik, 1958/1959, p. 32)

Além da óbvia influência marxista, nosso propósito no presente artigo é de explicar, particularmente, como o ativismo pedagógico, propugnado por John Dewey, também perpassou as experiências educacionais russas dos primeiros tempos revolucionários, na medida em que a sua obra foi uma das referências para os estudos e pesquisas de Krupskaya. Inseridas em realidades díspares, as experiências educacionais norte-americana e russa transcorridas nas primeiras décadas do século XX foram marcantes e similares quanto ao período histórico, mas ideologicamente opostas. A erradicação do analfabetismo e a construção do sistema escolar após a Revolução de 1917 foram políticas praticadas em nome do socialismo. A renovação pedagógica nos Estados Unidos da América (EUA) foi um fenômeno do capitalismo industrial em ascensão. Esse país, desde o final do século XIX, universalizava a escola secundária e iniciava um tipo novo de educação superior (Colleges), portanto, já contava com um aparelho escolar consolidado. Assim, se nos EUA, segundo

1 Podem ser encontradas diferentes grafias do nome dessa autora, que no Brasil é mais conhecida simplesmente como Kruspskaya. 
Dewey, era preciso renovar o sistema educacional, na Rússia Soviética, tratava-se de construí-lo.

De fato, nos EUA o crescimento econômico após a Primeira Guerra Mundial (1914-1918) suscitou a crítica sobre a defasagem do aparelho escolar diante do desenvolvimento industrial. Foi nesse contexto das primeiras manifestações econômicas, sociais, políticas e culturais do capitalismo monopolista que John Dewey iniciou suas formulações sobre a necessidade de uma nova escola, propondo um método que se tornou o divisor de águas no pensamento pedagógico contemporâneo do mundo ocidental. Além de vasta obra publicada, ele difundiu suas ideias proferindo conferências e cursos em países como Japão, China, México, Turquia e Rússia.

A viagem de John Dewey à Rússia, em 1928, ocasião em que se completavam dez anos do esforço educacional iniciado com a Revolução de Outubro de 1917, pode ser inscrita no rol das atividades político-pedagógicas que ele exerceu durante toda a vida, já que foi descrito por Lorenzo Luzuriaga (1980, p. 250) como um intelectual defensor da democracia, que "esteve a serviço de ideias mais nobres e elevadas, tanto no âmbito político-social, como no pedagógico". De fato, ao lado da atividade teórica, que exerceu até a morte,

manteve intensa vida pública, sempre defendendo causas progressistas. Em 1937, presidiu a comissão pública que deveria investigar a veracidade das acusações contra Leon Trotsky, concluindo por sua inocência. Em 1941, já com 82 anos de idade, revoltou-se contra a proibição de Bertrand Russell (1872-1970) [de] lecionar no City College de Nova York. (Mariconda, 1980, p. VI)

No plano teórico, como se sabe, inicialmente sofreu forte influência de Hegel, a maior expressão da filosofia clássica alemã. Depois, o centro de seu pensamento passou a ser a concepção que ele mesmo chamou de "instrumentalismo", para distinguir-se do pragmatismo de Peirce e William James, dos quais partira. Apesar disso, seu ponto de partida foi também uma crítica às filosofias especulativas. Para Dewey, o conhecimento não é mais do que atividade dirigida e parte funcional da experiência. $^{2}$

Depois de realçar sua rica contribuição, designando-o como o maior nome da pedagogia do século XX e reconhecendo que raramente um pensador mostrou tamanha coerência entre as premissas teóricas e as opções práticas, Manacorda assinala que lhe faltou, porém, a visão dialética sobre o Estado capitalista, uma vez que ele não o compreendeu como negativo em si mesmo, ao passo que, para Marx, é esse Estado que precisa ser superado, conforme lemos:

Dewey, como Marx, baseia-se no desenvolvimento econômico e produtivo, mas falta-lhe aquela análise dialética do real e de suas contradições, cujas explosões, segundo Marx, provocariam as mudanças, e aquela perspectiva, talvez utópica mas fortemente estimulante, de uma totalidade de indivíduos totalmente de-

2 Sobre as críticas de Dewey à escolástica medieval e os elogios ao empirismo do século XVI, digno de nota é John Dewey, A filosofia em reconstrução (1958, p. 55 et seq.). 
senvolvidos; no lugar dessa análise, há nele a conclamada finalidade de educar o indivíduo para participar da mudança, concebida como a progressiva evolução de um estado de coisas em si positivo. (Manacorda, 1989, p. 320)

Estabelecida a distinção entre os contextos históricos nos quais transcorreram a experiência norte-americana e a russa, passaremos à influência do ativismo pedagógico na experiência educacional russa dos primeiros tempos da revolução socialista.

\section{A EDUCAÇÃO NOS PRIMEIROS TEMPOS DA RÚSSIA SOVIÉTICA: ANOS QUE VALERAM SÉCULOS}

Anos que valeram séculos. Talvez essa seja a frase que melhor expresse o esforço educacional da Rússia Soviética no difícil contexto para erradicar o analfabetismo; construir um sistema nacional de escolas públicas, expandir o saber científico, as artes e, ainda, instituir a educação tecnológica e física, um programa gigantesco diante das condições materiais do país e que, mesmo assim, começou a ser implantado em 1918, antes do término da Guerra Civil (1918-1920) e da instauração da Nova Política Econômica (NEP). Introduzida em 1921, a NEP instituiu formas de capitalismo de Estado mediante a retomada do crescimento das forças produtivas, pois, de acordo com Lênin, sem o aumento da produção, a revolução não venceria.

A partir de então, os desafios passaram a ser os relacionados com a realização das tarefas democrático-burguesas que ainda não haviam sido realizadas na Rússia, ou seja, as três outras "revoluções" que complementavam a Revolução de Outubro: industrial, agrária e cultural. Até 1861, prevaleciam na Rússia czarista as relações feudais de produção. A pátria de Tolstói era um dos países mais atrasados da Europa, onde os camponeses podiam ser vendidos e comprados como gado, como coisas. A passagem do agrarismo para o industrialismo, após 1917, tinha de superar essas mazelas e a destruição humana e material causada pela Guerra Civil; era imperioso construir, com base em modernas tecnologias, a chamada indústria pesada, a única capaz de impulsionar o desenvolvimento da indústria leve, reestruturar a agricultura, elevar o bem-estar social do povo soviético e aumentar a capacidade de defesa militar do país. Mas, sem as fontes de energia para movimentar as fábricas, não haveria possibilidade de se realizar a moderna industrialização. Assim, teve início uma ampla mobilização para a construção de gigantescas hidrelétricas tanto na parte europeia quanto asiática do território soviético. Energia elétrica e indústria de base, essas foram as duas primeiras grandes iniciativas de modernização econômica que arrancaram a Rússia Soviética do atraso em que se encontrava.

Quanto ao processo de transformação da agricultura por meio da moderna técnica de produção, uma das primeiras medidas adotadas pelo Estado soviético foi a liquidação da propriedade latifundiária sobre a terra e o perdão das altas dívidas anuais que os camponeses pagavam para os grandes proprietários pela compra ou arrendamento das terras. No entanto, a necessidade de aumentar a produtividade agrícola, mediante o uso de técnicas produtivas fundadas em conhecimentos científicos 
e tecnológicos modernos, esbarrava na dispersão de recursos materiais e na tradição camponesa patriarcal que secularmente reinava nas aldeias do vasto império czarista. Premido pela demanda de erradicação da fome, o Estado Soviético colocou em prática um acelerado processo de coletivização da agricultura, no qual operou a concentração das terras em grandes fazendas coletivas de agropecuária e a mecanização industrial da produção gerada.

Concomitante a essa construção econômica e em meio à ruína causada por dois trágicos acontecimentos - a Primeira Guerra Mundial (1914-1918) e a Guerra Civil, que se fez acompanhar da invasão de forças armadas da Europa Ocidental, dos EUA e do Japão -, teve início o esforço pela instrução pública e a escola de Estado na Rússia Soviética. Além disso, era preciso promover a formação profissional tecnológica dos filhos dos camponeses e a mobilização social pelo fim do analfabetismo. Os primeiros resultados surgiram já nos anos que se seguiram ao fim da Guerra Civil: no domínio da instrução pública, a população alfabetizada cresceu de $32 \%$, em 1920, para 40\% nos fins de 1926. Nas aldeias funcionavam mais de 22 mil salas de aulas; o rádio e o cinema começaram a incorporar-se aos hábitos dos camponeses. Para aquilatarmos o significado desses números, lembremos que na Rússia czarista, na encruzilhada dos séculos XIX e XX, sete em cada dez habitantes (sem contar as crianças com menos de 9 anos de idade) não sabiam ler nem escrever (Bittar; Ferreira Jr., 2011, p. 380 et seq.).

Na Ásia Central, no norte da Sibéria e em certas regiões orientais dos confins do imenso império, a situação era ainda pior: nove em cada dez habitantes eram analfabetos. Apesar desse quadro desolador que exigia grande quantidade de educadores, entre 1800 e 1913, os institutos pedagógicos da Rússia formaram apenas seis mil pessoas. Em 1917, a formação de pedagogos aumentou, mas mesmo assim os respectivos estabelecimentos de ensino só proporcionavam, no máximo, $25 \%$ dos professores de que necessitava o país. Em 1906, a revista Boletim de Educação, editada pelo Ministério da Educação czarista, fizera a estimativa segundo a qual, na parte europeia da Rússia, toda a população só poderia ser alfabetizada dentro de 120 anos; na Sibéria e no Cáucaso, dentro de 430 anos; na Ásia Central, dentro de 4.600 anos.

O sistema de ensino secundário na Rússia czarista, por sua vez, era heterogêneo. Além de ginásios, onde predominava o ensino de humanidades e línguas antigas, existiam escolas de ensino profissional, nas quais se dava preferência a matérias das ciências naturais, matemática e disciplinas técnicas. Existiam ainda institutos para moças nobres, corpos de cadetes, e outros estabelecimentos de ensino para as elites, que, além de outros conhecimentos, aprendiam as maneiras aristocráticas de viver.

Além do curso secundário completo, que proporcionava uma preparação geral bastante sólida, embora um tanto unilateral, existiam escolas primárias sem continuidade com as secundárias: as eclesiástico-paroquiais e as destinadas principalmente a filhos de operários e camponeses, chamadas "zemstvos". Supunha-se que ao povo bastavam apenas conhecimentos elementares, como ler, escrever, fazer contas simples e ter formação moral de cunho religioso. Terminado o primário, formalmente não se proibia realizar o secundário, mas, na prática, nesse caminho interpunham-se barreiras quase intransponíveis. Na Rússia de 1913, com uma população de 160 milhões de habitantes, havia apenas 434 ginásios e 276 escolas 
profissionais, todos eles frequentados por apenas 160 mil crianças e adolescentes. Em 1915, apenas oito milhões de crianças frequentavam a $1^{\mathrm{a}}, 2^{\mathrm{a}}$ e $3^{\mathrm{a}}$ classes do ensino primário; e apenas 948 mil chegavam à $4^{\mathrm{a}}$ classe (Malkova, 1985, p. 9 et seq.).$^{3}$

Nos primeiros anos após a Revolução de 1917, todos os flagelos abatiam-se sobre o país: fome, frio, desemprego, inflação. Para uma população de 160 milhões de habitantes, faltavam víveres, combustível e artigos manufaturados de primeira necessidade, começando por fósforos e terminando por roupas. Nesse quadro de penúria, às vezes os alunos escreviam com carvão vegetal ou tinta feita de fuligem. Para escrever e imprimir livros, serviam-se de papel de embrulho; como não havia cartilhas, aprendiam a ler soletrando textos de jornais ou revistas. Como faltavam professores, as suas funções ficavam a cargo de ajudantes voluntários, que, muitas vezes, tinham aprendido a ler e a escrever havia pouco tempo. Assim começou a obra que exigiu esforços incansáveis, e um dos resultados mais impressionantes foi que "de 1923 a 1939, na União Soviética aprenderam a ler e a escrever mais de 50 milhões de analfabetos e cerca de 40 milhões de semianalfabetos" (idem, p. 11 et seq.).

Já no âmbito da plataforma educacional revolucionária, uma das principais demandas era a questão relacionada a educação e trabalho, ou seja, a nova concepção pedagógica exigia uma revisão estrutural dos conteúdos relacionados entre trabalho e educação no âmbito da escola socialista. Era necessário criar novos programas que proporcionassem o conhecimento das leis básicas do desenvolvimento das ciências da natureza e da sociedade humana e, portanto, gerar uma nova racionalidade que fosse capaz de estabalecer as múltiplas e complexas conexões existentes entre os próprios homens e a natureza nos marcos da sociedade socialista, e, para isso, era essencial desenvolver diferentes métodos e formas organizativas do processo de ensino e de aprendizagem, o que possibilitaria estabelecer relações orgânicas entre a escola e a nova vida societária. Em síntese: o programa pedagógico revolucionário propugnava criar vínculos relacionais entre educação geral, de cunho humanístico, e trabalho socialmente útil, isto é, defendia a ligação orgânica da teoria com a prática.

No contexto dessa experiência educacional tão incomum, haveria espaço para o ativismo pedagógico?

\section{A ESTAÇÃO DO ATIVISMO PEDAGÓGICO NA ESCOLA SOVIÉTICA}

Começaremos este item pelo estudo da obra de Anatoli Lounatcharski porque, ao desempenhar a função de chefe do Comissariado do Povo para a Instrução, ele dispensou grande atenção à escola primária, e é nela que se encontram mais referências ao método de Dewey. Entre artigos e discursos pronunciados no período de 1918 a 1927, constatamos que, quando a questão se refere ao método,

3 Durante o século XIX, os países da Europa Ocidental empenhavam-se na universalização da escola primária, expansão que havia começado no século XVII sob o impacto das reformas religiosas. A escola secundária só foi universalizada na primeira metade do século XX, como foi o caso da Inglaterra e da França. Comparativamente, portanto, não houve esforço para expandir a escola primária russa no século XIX. 
é recorrente $\mathrm{a}$ alusão $\mathrm{a}$ Dewey e às experiências ocidentais que adotaram o ativismo pedagógico.

Para Lounatcharski, que considerava como grandes pedagogos Rousseau, Pestalozzi, Herbart e Fröebel, "Não podemos contentar-nos com os estudos tal como foram no passado. Devemos encontrar o caminho para uma escola viva" (Lounatcharski, 1988e, p. 167). Sobre o ensino prático na formação da criança, ele distinguia a escola primária da secundária: na primeira, o ensino devia comportar o jogo e a assimilação dos conhecimentos elementares no decurso de uma atividade que provem da brincadeira e que vai se tornando cada vez mais séria. "Quando Dewey descreve como devem preparar-se os alimentos e como se podem deste modo dar-se excelentes lições de química e física, de botânica e de zoologia, de higiene e de fisiologia, tem profundamente razão" (Lounatcharski, 1988b, p. 119).

Obviamente, essas alusões não perdiam de vista o caráter burguês da orientação pedagógica nos EUA. Em diversos de seus discursos, esse aspecto é realçado, como em maio de 1923, na Assembleia Geral dos Sindicatos de Empregados da Instrução Pública e de Artistas, comparando as políticas educacionais da França e Alemanha, cujas burguesias não haviam ousado implementar totalmente sua própria escola com a Suíça e Noruega, que, segundo Lounatcharski, haviam instituído uma escola camponesa "pequeno-burguesa". E arrematou: "Existe um só país onde a burguesia mais ou menos instalou livremente a sua própria escola, uma escola autenticamente burguesa: é a América" (Lounatcharski, 1988d, p. 142-143). Em consequência, ele sublinhava sempre o caráter classista dessa escola.

Demarcando essa distinção, desde 1918, Lounatcharski dedicava-se a instituir a escola única na Rússia, com a seguinte feição: o objetivo dos jardins de infância e dos primeiros anos de escolaridade era o de tornar racionais os jogos das crianças. Encenando, cantando, dançando, modelando e desenhando, as crianças aprendem, e, de acordo com ele, a concepção primeira do princípio do trabalho é a de que a criança devia instruir-se por meio do trabalho, isto é, por métodos vivos. No entanto, o ensino escolar ignorava que a brincadeira fosse um método autodidata:

A criança quer correr, façam-na sentar-se em seu lugar; a criança quer ela própria criar, ocupar-se de uma coisa que lhe interessa - façam-na decorar latim! Em suma, é travada uma luta contra a própria natureza da criança. A nossa concepção é completamente diferente. (Lounatcharski, 1988c, p. 91-92)

Examinemos, nesse ponto, a possível relação entre o que afirmava Lounatcharski e o método de ensino criado por Dewey. Como sabemos, os conceitos basilares de sua pedagogia são:

1) Não deve haver nenhuma separação entre vida e educação. As crianças não estão, em um dado momento, preparando-se para a vida e, em outro, vivendo. Vida, em condições integrais, e educação são o mesmo;

2) A finalidade da educação é mais e melhor educação, no sentido de maior capacidade em compreender, projetar, experimentar;

3) Para que a educação se realize, a escola deve assumir a feição de uma comunidade em miniatura, ensinando situações de comunicação entre as pessoas, e de cooperação entre elas, visando a propósitos comuns. 
O corolário disso é que a escola deve estar conectada com a vida social em geral. Ademais, outro aspecto a notar na definição de Dewey é que o fim (resultado) da educação identifica-se com seus meios (processo), do mesmo modo que os fins da vida identificam-se com o processo de viver. É por isso que, segundo Anísio Teixeira, a concepção de Dewey não se confunde

com os conceitos tradicionais de que a educação é um desdobramento de forças latentes internas, ou uma formação pela aplicação de forças ou influências externas, sejam físicas, naturais, sejam culturais e históricas [...] nos termos de Dewey, a educação não se confunde com qualquer desses processos de preparação. (Teixeira, 1980, p. 116-117)

No que diz respeito à escola primária russa, segundo Lounatcharski, a tendência pedagógica era a mesma iniciada nos jardins de infância, mas com o cuidado de se passar da brincadeira ao trabalho no sentido mais lato do termo, conduzir o assunto de modo a que as crianças adquirissem conhecimentos brincando, ao mesmo tempo em que trabalhassem, sem atingir a fadiga. Os professores deveriam deixar os alunos juntar-se em grupos, escolher uma ocupação, e guiá-los na finalidade da aquisição de novos conhecimentos. Depois de fixado um objetivo preciso, deveriam dar às crianças material preparado para estudo e conclusões. "O novo método consiste em excursões, passeios, desenhos, modelismo e em toda espécie de processos de trabalho por intermédio dos quais a criança enriquece por si mesma a sua experiência" (Lounatcharski, 1988c, p. 92). A escola deveria alimentar a criança sempre com seus próprios interesses e, assim, ter mais certeza de levá-la ao círculo dos conhecimentos e aptidões práticas.

Quanto à relação entre conhecimento e experiência, lembremos que, prevalecendo no interior do movimento ativista interpretações de tipo individualista, espontaneísta e anti-intelectualista sobre sua obra, o próprio Dewey interveio para corrigi-las escrevendo Experiência e educação (1937). Nesse livro, explicou sua teoria de educação mediante a experiência e expôs o sentido e a orientação que devem ter no ensino os programas e planos de estudo, tomando equidistância entre os que pretendiam sua supressão e os que preconizavam sua vigência.

Dewey procurou demonstrar que a escola tradicional é algo de fora para dentro, de cima para baixo, além do alcance da experiência do educando, e lembrou que a atividade livre e o aprender mediante experiência foram dois pontos que a educação nova tomou emprestado de Rousseau. A unidade da nova pedagogia, segundo ele, fundamenta-se na relação entre experiência e educação, daí a necessidade de um conceito correto de experiência. Se a escola tradicional diverge em muito da escola ativa, isso não significa, contudo, que deva haver entre ambas uma oposição radical.

De fato, a suposta oposição entre as duas correntes já havia merecido tratamento sistemático do autor quando, em 1902, abordando os exageros da velha e da nova educação, afirmou que uma parte das escolas pedagógicas fixava sua atenção na importância das matérias dos programas, e outra, na experiência própria da criança. A oposição entre a criança e o programa de ensino pode expressar-se também pelos termos "disciplina" contra "interesse" e "direção e controle" contra 
"liberdade e iniciativa". De acordo com Dewey (1980, p. 140), "disciplina é a divisa dos que engrandecem o curso do estudo: interesse, a daqueles que têm por bandeira a criança. O ponto de vista dos primeiros é o ponto de vista lógico; dos segundos, o psicológico". No entanto, para ele, o problema, assim colocado, estava mal posto, pois as duas condições estão necessariamente relacionadas no processo educativo. Qual é, pois, o problema? Segundo Dewey (idem, p. 141):

não é outro senão o de afastar a ideia funesta de que existe uma distinção qualitativa (não apenas de grau) entre a experiência infantil e as várias matérias de que se constrói o plano de estudos. Do lado da criança, basta ver que sua experiência já contém elementos - fatos e conhecimentos - exatamente da mesma natureza daqueles que compõem a matéria de estudo; e, o mais importante, que a sua experiência já implica as atitudes, motivos e interesses que levaram a organização da disciplina ao nível que hoje.

Ele prossegue assinalando que o perigo da nova educação estava em considerar as forças e os interesses presentes na criança como coisas de significação definitiva, além de tomar o desenvolvimento de um modo vazio e formal.

Tal consideração se faz importante porque na Rússia soviética desse período, a preocupação central no que diz respeito à instrução era em relação a seu papel de difusão do conhecimento, portanto, incompatível com um ensino vazio e formal. Assim, para evitar tanto o vazio de conhecimentos quanto o defeito essencial da velha escola - o afastamento do ensino escolar da vida e o isolamento das matérias umas em relação às outras -, foi instituído nas escolas russas, a partir de 1923, o "método de conjunto". Tal método consistia em agrupar o material didático em torno de um núcleo de conhecimentos: era a partir daí que a criança acumulava e aprofundava suas noções sobre o mundo que a rodeava. Os autores desses programas acreditavam que eles tendiam para a síntese do material didático em torno de três temas principais: natureza, trabalho, sociedade. Os programas estavam centrados na atividade laboriosa do homem, a qual devia ser estudada em ligação com a natureza como objeto dessa atividade e com a vida social como produto desta. Desse modo, atingia-se a finalidade fundamental do ensino, isto é, o conhecimento dos fenômenos da vida em suas conexões e interação. Segundo Lounatcharski (1988h), esse método, por ele também chamado "complexo", resultado dos trabalhos pedagógicos daqueles primeiros anos, era utilizado na escola austríaca, em parte na alemã e estava em vias de elaboração na América, onde o próprio John Dewey deu o primeiro impulso à sua aplicação prática. "Actualmente uma grande comissão de 30 dos maiores pedagogos americanos está para vir cá a fim de conhecer o nosso sistema de ensino" (idem, p. 200). Ele se refere aqui à viagem de Dewey à Rússia, que ocorreria em 1928.

O "método de conjunto", no entanto, encontrava resistência, especialmente se considerarmos que a maioria das escolas localizava-se nas aldeias russas. A esse respeito, insistindo na necessidade de todos aprenderem a ler e a escrever, Lounatcharski destacava as dificuldades que enfrentavam na alfabetização dos camponeses, que resistiam tanto à escola em si quanto à novidade do método. Para superá-las, alertava 
para o fato de que a novidade da escola não poderia consistir em não ensinar a ler e a escrever, mas, sim, em um programa de conjunto.

No caso do campesinato, os pais não gostavam quando seus filhos lhes contavam que haviam feito excursões, escultura, desenho e canto, pois a eles só interessava o ler, o escrever e o contar. Além disso, não aceitavam a extinção do ensino do catecismo nem a proibição imposta pelo Estado soviético de bater nas crianças. Para Lounatcharski, tal como havia sido feito "na Suíça burguesa”, a escola soviética no campo, considerando esse programa de conjunto, deveria ter por objetivo a boa instrução elementar, simples e sólida, e facultar conhecimentos agrícolas indispensáveis para auxiliar a agricultura. "É por intermédio das crianças que a América educa o seu fazendeiro que desenvolveu uma economia inacessível ao nosso camponês" (1988e, p. 169).

De acordo com ele, os americanos tinham perfeitamente razão ao afirmarem que é preciso desenvolver habilidades manuais, por isso, na escola primária era importante até mesmo o "autosserviço", compreendido como pequenas reparações na escola, trabalho na horta ou com alguns pequenos animais domésticos, mas sem que as crianças fossem sobrecarregadas e desde que procedessem de forma que se enriquecessem com a experiência. Sobre esse propósito, de acordo com Lounatcharski (1988d, p. 148-149), os americanos haviam feito o que podiam:

Não têm nem podem ter escola única, mas quanto à escola do trabalho no sentido do predomínio dos métodos ativos de assimilação, os americanos fizeram muito. Podemos atualmente ir lá buscar muitas coisas, e sabemos até que ponto esse método de educação pelo trabalho, as excursões, o desenho, a elaboração autônoma por uma criança ou grupo de crianças de um tema, os memorandos e análises temáticas, as discussões, o modelismo, etc, sabemos até que ponto este método enraíza profundamente na criança a informação adquirida, evitando quase totalmente o risco de esquecimento e as sequelas de uma queda no nível de conhecimentos, da ignorância, o que é o fenômeno geral da nossa antiga escola. Mas a nossa concepção de escola do trabalho não fica por aqui.

A escola única do trabalho deveria ultrapassar esse aspecto. Se para a criança essas atividades eram apropriadas e necessárias, coisa diferente deveria se passar no nível secundário. Novamente tomando como parâmetro a experiência norte-americana, que, segundo ele, tinha a escola secundária mais bem concebida, assinala Lounatcharski (1988c p. 89):

devemos analisar de perto a maneira como os burgueses americanos organizaram as escolas para as suas crianças. Muito do que introduzimos na nossa escola única do trabalho é uma aplicação socialista dos métodos em curso nas melhores escolas burguesas americanas.

Para Lounatcharski, a escola secundária deveria ter em vista o ensino do trabalho em si. Esse ensino, diferentemente do técnico, em que apenas se trata de fazer 
de um aluno um bom operário, deveria fazer parte da instrução geral, pois não se tratava de formar um bom torneiro ou bom operário têxtil, mas de ensinar o aluno a conhecer o trabalho. O objetivo consistia em dar ao adolescente uma ideia do que é um trabalho cientificamente organizado. Por isso, enfatizava, "à nossa escola chamamos escola única do trabalho" (1988c, p. 91). Assim, estabelece a seguinte crítica à escola secundária americana:

A escola ministra conhecimentos exclusivamente práticos. A história lá [nos EUA] é ensinada no espírito patriótico de classe, [...] aos doze anos, um rapaz não deve aprender mais nada, entra como aprendiz para a manufatura, para a fábrica, para a oficina, é corrido da escola, a sua instrução está terminada. (idem, p. 85)

Para um homem de alta cultura como Lounatcharski, que mesmo durante os duros tempos da guerra civil não deixou de sonhar com um ser humano amplamente instruído e para quem a especialidade não podia matar a cultura geral, esse aspecto prático da escola secundária norte-americana era um dos mais condenáveis. De acordo com ele, a cultura deveria ter lugar central no projeto da revolução socialista, como se verifica no seguinte excerto:

Temos necessidade de cultura, começando na alfabetização e acabando na ciência, uma cultura no domínio do pensamento e uma cultura em matéria de sentimento. Aqui tenho a dizer-vos que o lugar que a ciência ocupa no domínio do pensamento, corresponde ao da arte no domínio do sentimento. [...] E se temos, portanto, necessidade de cultura para progredir rumo ao comunismo, a inversa é igualmente verdadeira: o comunismo será absolutamente desprovido de sentido se não servir a cultura. Cultura, instrução, ciência, arte - não são apenas outros tantos meios para atingir os nossos fins. São ao mesmo tempo a nossa mais nobre finalidade. (1988e, p. 162)

Em outro momento, foi ainda mais incisivo:

A fome física que atualmente sentimos é menos perigosa que a fome espiritual, que esta inanição do povo no plano cultural. [...] É necessária uma massa de conhecimentos para saber o que é preciso demolir e como fazê-lo, para saber como pôr um edifício em obra. Compete à escola ensinar os rudimentos do conhecimento sem esquecer que o ideal não é preparar o homem para esta ou aquela especialidade, mas fazer dele um combatente pelo humanismo. (1988a, p. 51-52)

Essa formação, segundo ele, deveria começar com as crianças, em relação às quais, desde que tivessem idade que lhes permitisse semelhante abordagem, o ensino deveria preocupar-se com o conteúdo e também com a forma. Em outras palavras, os mestres deveriam chamar a atenção das crianças para a musicalidade, o colorido e a expressividade desta ou daquela frase, para a plasticidade, o dinamismo desta ou daquela figura, tudo isso como parte da leitura das obras clássicas e da aquisição 
do que ele designava como "arte verbal". Nos ensaios dos próprios alunos, insistia em que era preciso levá-los a expor de maneira espontânea e, portanto, literária os acontecimentos que eles realmente haviam vivido (realismo espontâneo). Ele destacava que a narrativa literária do vivido é uma grande força. Além disso, a escola deveria proporcionar livre curso à fantasia:

Os sonhos são próprios da infância e da adolescência (na juventude sob uma forma algo diferente). Os sonhos, a começar pelas mentiras e pelos mitos infantis e indo até aos jovens romances vivos, emotivos, onde é expandida a nostalgia de uma vida ainda por viver que são uma espécie de manobras íntimas, um jogo, um exercício que antecipam a plenitude de ação do homem maduro. (Lounatcharski, 1988f, p. 186)

Em seguida, alude ao fato de que viviam tempos duros, práticos, técnicos, de luta, e que, por essa razão, alguns jovens achavam mesmo que não tinham necessidade de paixão, do patético, de entusiasmo, da necessidade de simpatia, compaixão e amizade pelo ser humano, e criticava: "Isto são caminhos nocivos, é o secar da consciência do homem, é caminhar para a automatização, é uma tentativa de o assimilar à máquina, é fordismo e não marxismo, é o ideal dos EUA e não o da URSS" (idem, p. 187).

A formação cultural ampla, característica da pedagogia marxista, volta a preocupar Lounatcharski no balanço que fez, em 1928, dos dez anos da educação soviética. Isso porque o avanço industrial do país contribuíra para difundir a concepção de escola unicamente como instrumento de reprodução da mão de obra, ideal social batizado de "nova América" que, no plano educativo, encarnava-se no "homem que saber apertar um parafuso". Esse ponto de vista dos que encaravam o socialismo como "socialização do homem" estava próximo dos ideais educativos dos partidários do "parafusismo", como os chamava Lounatcharski. Em seu balanço, revela a inconsistência dessas concepções e mostra que o socialismo, longe de ampliar a "mecanização" e a "socialização do homem", deveria suscitar o desenvolvimento de sua individualidade fundindo ao máximo todas as "vontades humanas" em uma "força organizada única". "É este objetivo que deve perseguir a educação da juventude, em nome de que nós lutamos, nós existimos, sem a qual não nos valeria a pena viver e combater" (1988g, p. 194).

Outra referência à experiência norte-americana foi feita no artigo "Premissas sociológicas da pedagogia soviética”, publicado em 1927 por ocasião dos dez anos da revolução e no qual Lounatcharski levantou uma série de problemas metodológicos e teóricos. Enfatizando a necessidade da participação da escola na vida social, sublinhou que, mesmo nos países de democracia burguesa, seria possível:

não encarcerar as crianças em estudos escolares escolásticos. Mas Dewey, pedagogo bem conhecido, que é, justamente partidário da escola do trabalho e, em particular da escola social, declara no seu livro As escolas do futuro, que mesmo na América ele só conhece ao todo oito ou nove escolas que neste aspecto poderiam ser consideradas satisfatórias. (idem, ibidem) 
Para ele, no entanto, comparativamente ao que praticava a escola norte-americana no ramo da agricultura, experiência conhecida na Rússia por meio do livro Os colégios agrícolas dos Estados Unidos, de Tulaikov, que havia visitado os EUA em 1924 (idem, p. 195), não se tratava de uma simples participação da escola na vida, nem que ela estivesse atrasada em relação à vida que, por assim dizer, deveria puxá-la como um rebocador sem dela se separar. Nas condições de baixo desenvolvimento econômico da Rússia soviética, ele insiste em que a escola podia, desde o início, desempenhar seu papel estimulando o trabalho social e cooperando com ele.

Quanto ao ativismo pedagógico na atuação de Krupskaya, em decorrência de sua vivência no exílio antes da revolução, ao se empenhar na introdução da escola soviética segundo a concepção marxista da união entre educação intelectual, física e tecnológica, valorizou os métodos ativos da escola ocidental. Pois, para ela, a educação soviética "sempre esteve direcionada para o desenvolvimento de todas as capacidades de cada criança, elevando o nível de sua atividade e de sua consciência, em prol do desenvolvimento pleno de sua personalidade, de sua individualidade" (Krupskaya apud Prozorov, 1958/1959, p. 35). Aliás, nos artigos e discursos de Lounatcharski aqui citados, são frequentes as alusões a Krupskaya no que se refere a esse aspecto. A respeito das pequenas oficinas junto a cada escola e grandes oficinas escolares adaptadas às necessidades de todo um bairro, como faziam os franceses, por exemplo, Krupskaya destacou que não deixavam de ser um paliativo, que não se tratava de uma abordagem marxista, mas que, onde fosse possível instalá-las, seriam bem-vindas.

Em artigo de 1927, ela chamou a atenção sobre a importância de saber organizar o canto, os jogos, a leitura em conjunto, pois tudo que fosse feito em conjunto com as crianças as aproximaria umas das outras. Mas advertia para o fato de que essas atividades em conjunto não podiam se limitar a festas: deviam ser experiências que proporcionassem a emoção do viver o cotidiano em coletividade. Além disso, era preciso dar menos importância à forma do que ao conteúdo, e criticou os professores que acreditavam que apenas os livros ensinassem: "Há excursões e jogos que ensinam a ver a vida. No trabalho extraescolar, é preciso combinar os passeios e excursões com a observação da natureza, das pessoas e da vida circundante. Não temos feito isso. Em nossos círculos predominam educação física e teatro" (Krupskaya, s.d.a, p. 90). Acrescentava ainda que deviam dar atenção aos jogos, pois alguns dificultavam o desenvolvimento das habilidades coletivas e, em vez de unir as crianças, as separavam.

Depois, ao escrever "Hay que preocuparse del desarrolo multiple de los niños", no qual admite que na Rússia conhecia-se muito pouco acerca das inquietudes das crianças e das peculiaridades de cada idade, enfatizou: "Se não conhecemos as peculiaridades da idade, o que interessa às crianças em uma e outra idade e seu modo de perceber o que as cerca, não teremos êxito em nosso trabalho" (Krupskaya, s.d.b, p. 95). Nesse mesmo artigo, mostrou preocupação com a formação cultural das crianças e dos adolescentes esclarecendo que "não se deve predeterminar desde cedo se uma menina será bailarina e um menino engenheiro. Devemos nos preocupar com todas as crianças e dar-lhes o melhor que pudermos" (idem, p. 96). 


\section{O CARÁTER POLÍTICO DA EDUCAÇÃO SOVIÉTICA NA DÉCADA DE 1920 E SUA CONEXÃO COM A VIDA SOCIAL}

Como resultado de sua viagem à Rússia, em 1928, John Dewey publicou Impressions of Soviet Russia and the Revolutionary World, afirmando que escreveu sobre o que viu, e não sobre aquilo de que ouviu falar. Comparando o sistema nacional das escolas soviéticas com o sistema das "progressive schools" de outros países, com os quais, segundo ele, as escolas soviéticas tinham muito em comum, concluiu que a diferença era o compromisso social destas. Nesse aspecto, salientou que a ideia de que a escola na qual estudantes, estudos e métodos devam estar conectados com a vida social, em vez de estar isolada, é uma das mais antigas teorias educacionais. Assim sendo, o que caracterizava a educação soviética não era a ideia de vincular as atividades escolares às atividades sociais extraescolares, mas o fato de que pela primeira vez na história havia um sistema oficialmente organizado sob esse princípio. Para ele, a resposta ao como e por que as autoridades educacionais haviam sido capazes, em tão pouco tempo, de desenvolver tal modelo de educação com tão escassos precedentes nessa matéria era a de que puseram o aspecto econômico e o industrial em função da vida social.

Já em sua primeira grande obra $A$ escola e a sociedade (1899), escrita em um momento de transformação produtiva e de crescimento econômico dos Estados Unidos, Dewey preconizou que a escola não podia ficar alheia aos problemas da sociedade industrial moderna, mas ligar-se intimamente ao "progresso social". Em contexto inteiramente distinto do norte-americano, notamos preocupação semelhante em Lênin, pois a relação da escola com a vida social, realçada por Dewey como um aspecto orgânico do sistema escolar russo, está muito presente em sua obra. Na condição de exilado, durante a Primeira Guerra Mundial, ele não apenas se interessou pela educação dos países onde viveu, mas escreveu sobre a instrução dos jovens. Um dos pontos de maior relevo em sua concepção de educação era o de que ela jamais deveria ser apolítica. Depois de sua volta clandestina à Rússia e de ter liderado a revolução socialista, empenhou-se pessoalmente para que, em março de 1919, fosse aprovada a resolução que determinou:

1- Instrução geral e politécnica gratuita e obrigatória para todas as crianças e adolescentes dos dois sexos, até os 17 anos de idade; 2- Plena realização dos princípios da escola única do trabalho com o ensino na língua materna, estudo em comum das crianças dos dois sexos, absolutamente laica, livre de qualquer influência religiosa, que concretize uma estrita ligação do ensino com o trabalho socialmente produtivo, que prepare membros plenamente desenvolvidos para a sociedade comunista. (Manacorda, 1989, p. 314-315)

A obrigatoriedade da escola em um país com proporção de iletrados entre $90 \%$ e $95 \%$ era um desafio descomunal que a revolução herdara. ${ }^{4}$ A propósito, a

4 Jean-Claude Chesnais (1989, p. 146), elaborando um panorama do nível da alfabetização em todos os países da Europa, assinala que no final do século XIX, "em última 
ausência de uma revolução democrático-burguesa na Rússia, que, a exemplo dos países ocidentais, edificara um sistema nacional de escolas públicas, embora marcado com o selo da desigualdade, foi assim considerada por Lounatcharski (1988g, p.191), ao compará-la com a tarefa que tinham pela frente:

Nesta óptica [da revolução de outubro], proclamar o princípio da escola única é não só afirmar um princípio natural do socialismo que se edifica, mas também levar a cabo uma reforma democrática. A escola única, a igualdade do direito à instrução, é, propriamente falando, o último elo da revolução burguesa e, ao mesmo tempo, o primeiro elo da revolução socialista, do mesmo modo, por exemplo, que a nacionalização do solo ou a igualdade dos sexos em relação aos direitos políticos.

Interpretação semelhante encontra-se em Manacorda (1989). Ao realçar o elemento novo do marxismo, isto é, a relação instrução-trabalho (o grande tema da pedagogia moderna), que vai além do somatório de uma instrução tradicional mais uma capacidade profissional e tende a propor a formação de um homem omnilateral, afirma que o marxismo assumiu criticamente todas as instâncias da burguesia progressista:

universalidade, laicidade, estatalidade, gratuidade, renovação cultural, assunção da temática do trabalho, como também a compreensão dos aspectos literário, intelectual, moral, físico, industrial e cívico. O que o marxismo acrescenta de próprio é, além de uma dura crítica à burguesia pela incapacidade de realizar esses seus programas, uma assunção mais radical e consequente dessas premissas e uma concepção mais orgânica da união instrução-trabalho na perspectiva oweniana [de Robert Owen] de uma formação total de todos os homens. (idem, p. 296)

Nos discursos e artigos de Lênin após a revolução, notamos semelhante entendimento sobre a edificação do sistema escolar. Além disso, sua compreensão abrangia tanto o problema do método quanto seu caráter político e a conexão com a vida social. Ele abordou com frequência a questão da "ciência moderna" e os defeitos da "velha escola". No tocante ao método e aos conhecimentos transmitidos por esta, um dos registros mais inusitados é a transcrição que Manacorda fez sobre um diálogo entre o líder bolchevique e um menino, seu conhecido, de 12 anos, que começou com a pergunta:

"Que tarefas tiveste, e qual foi a aula?". O menino respondeu: "Tivemos três horas"“E quais?”"Matemática”."E depois?”"Depois, história”. "E que história?” “Do Egito" “E depois?” “E depois, língua alemã”. Lênin, então, começou a rir e

posição" estavam "a Europa Oriental (Bálcãs, Polônia) e a Rússia, com uma proporção de iletrados entre 90 e $95 \%$ ". 
disse para sua esposa, a pedagoga Krupskaya: “Tudo é ainda como antes”. (idem, p. 315)

A observação crítica de Lênin decorria do fato de que, além de consagrar apenas três horas aos estudos, a escola ainda privilegiava o ensino de história do Egito e da língua alemã quando era imprescindível mais aprendizagem do idioma russo. ${ }^{5} \mathrm{~A}$ crítica à "velha escola" é um dos aspectos principais de um discurso pronunciado em 1920, intitulado "As tarefas das uniões da juventude", no qual afirma que o socialismo deveria abolir tudo o que dela não servisse aos propósitos revolucionários, como seu caráter classista e o método autoritário, aproveitando, porém, tudo o que dela fosse útil para a edificação de uma educação a serviço da construção do socialismo na Rússia soviética. Nessa perspectiva, alerta a juventude para a necessidade de evitar uma postura pretensiosa segundo a qual, para construir o socialismo, seria suficiente o conhecimento ancorado nas palavras de ordem revolucionárias, descartando sumariamente a "ciência burguesa".

Esse discurso foi didaticamente construído em torno de dois eixos: o que aprender e como aprender, abordagem que surpreende, pois essas duas ordens de preocupação parecem ser típicas e exclusivas de pedagogos. Lênin, contudo, encarava os dois aspectos que envolvem o conhecimento como um ato integral de forma e conteúdo, além de estabelecer relação orgânica entre base material e educação, uma influenciando a outra.

Inicialmente ele afirma que a tarefa consistia em aprender. Mas aprender o quê? Essa é a primeira ordem de questões levantadas pelo líder bolchevique, para quem a tarefa de continuar a revolução que os sovietes haviam começado só poderia ser assumida pelos jovens comunistas se eles próprios se dispusessem a compreender os princípios marxistas e praticá-los, tarefa que nada tinha de simples. Ao contrário, seria ilusão pensar que alguém se tornaria um verdadeiro comunista nutrindo-se apenas de palavras de ordem. A formação intelectual demandaria esforço próprio para compreender os desafios da nova situação, combinando teoria e capacidade de intervenção prática, pois os princípios desvinculados da compreensão sobre a situação em que se encontrava a Rússia naquele momento de nada serviriam.

Por isso seria extremamente incorreta a simples assimilação livresca daquilo que dizem os livros [...]. Sem trabalho, sem luta, o conhecimento livresco do comunismo, adquirido em brochuras e obras comunistas, não vale absolutamente nada, porque prolongaria o antigo divórcio entre a teoria e a prática, esse antigo divórcio que constituía o mais repugnante traço da velha sociedade burguesa. (Lênin, 1980c, p. 387)

5 O aprendizado da lingual materna também foi um dos grandes problemas pedagógicos enfrentados no início da revolução. Em artigo de 1927, intitulado $A$ arte verbal na escola, Lounatcharski (1988f, p. 181 et seq.) alertou para o fato de que ainda era precária a "arte verbal" dos alunos e que, portanto, o ensino do russo precisaria avançar em três objetivos: 1) o conhecimento elementar da língua; 2) saber utilizar a língua para formular logicamente um raciocínio; 3) domínio da linguagem literária. 
Em seguida, indaga: "Que é que devemos tomar da velha escola, da velha ciência?". Para responder, começa a desnudar o caráter da velha escola, que, contrariamente aos propósitos proclamados, sendo classista, destinava aos camponeses e operários apenas treinamento, rudimentos para o trabalho, enquanto aos filhos da burguesia, o conhecimento desinteressado. "Por isso, ao rejeitar a velha escola, propusemo-nos a tarefa de tomar dela apenas aquilo que nos é necessário para conseguir uma verdadeira formação comunista" (idem, ibidem). Prosseguindo no exame sobre seus defeitos, assinala que ela era uma escola de estudo livresco, de "amestramento" e de aprendizagem de cor, que "obrigava as pessoas a assimilar uma quantidade de conhecimentos inúteis, supérfluos, mortos, que talhavam a jovem geração pela mesma medida" (idem, p. 388). No entanto, não bastaria aos jovens assimilar as palavras de ordem revolucionárias sem assimilar a soma de conhecimentos de que o marxismo é consequência, pois, segundo ele, o próprio Marx assimilara tudo o que a ciência anterior havia formulado, reelaborando de modo crítico o que o pensamento humano havia criado, retirando daí as conclusões que o pensamento limitado ao quadro burguês não podia retirar.

Estabelecendo o elo entre a educação e a base material da sociedade russa, Lênin indica que seria impossível edificar a nova sociedade sem restaurar a indústria e a agricultura. Mas seria preciso restaurá-las não à maneira antiga, e sim sobre uma base moderna, segundo a última palavra da ciência. Essa base era a eletricidade. Todavia, a eletrificação de todo o sistema produtivo russo era uma tarefa que não levaria menos que dez anos. Tirar a Rússia da escuridão era a obsessão de Lênin, não exclusivamente pelos resultados econômicos que a eletrificação acarretaria. $\mathrm{O}$ outro lado dessa moeda era: como alfabetizar um país às escuras? A esse respeito, em fevereiro de 1920, em uma conversa com o correspondente do jornal americano The World, Lincoln Eire, ele supôs que dentro de três anos estariam acesas na Rússia 50 milhões de lâmpadas incandescentes. "Suponho que nos Estados Unidos há 70.000.000 dessas lâmpadas, mas para um país onde a eletricidade se encontra ainda na infância, mais de dois terços desse número representam um enorme progresso" (Lênin, 1980b, p. 257).

A urgente eletrificação de toda a Rússia era um exemplo prático de como os jovens deveriam aprender e, ao mesmo tempo, era perfeito para lhes demonstrar a necessidade de vincularem estudo ao trabalho prático. Para explicar-lhes isso, Lênin alerta para o fato de que tal tarefa não poderia ser obra de analfabetos:

Compreendeis perfeitamente que a eletrificação não pode ser obra de analfabetos e que aqui não basta uma instrução elementar. Aqui não basta compreender o que é a eletricidade: é preciso saber como aplicá-la tecnicamente à indústria, à agricultura e a cada um dos ramos da indústria e da agricultura. Tudo isso temos que aprendê-lo nós próprios, e devemos ensiná-lo a toda a jovem geração trabalhadora. Esta é a tarefa que se coloca a cada jovem [...]. Ele deve compreender que só sobre a base da educação moderna a poderá criar, e que se não possuir essa educação o comunismo continuará a ser apenas um desejo. (idem, ibidem) 
Chamamos a atenção aqui para a expressão "educação moderna" empregada no discurso, o que nos remete a uma referência de Manacorda. Ao tratar da Escola Nova, ele menciona que Lênin, ouvindo o testemunho de um emigrante russo sobre as experiências americanas, teria se dirigido a Krupskaya com estas palavras:

É preciso estudar minuciosamente a experiência americana, é preciso fazer nosso tudo aquilo que se conseguiu nos países capitalistas, avaliá-lo com base no critério da nossa posição marxista e ver o que nos convém e o que não nos convém. (Lênin apud Manacorda, 1989, p. 313)

O segundo aspecto do discurso foi o relativo ao "como é preciso aprender". $\mathrm{Na}$ perspectiva de Lênin, os jovens deveriam ligar indissoluvelmente cada passo da atividade na escola, cada passo da educação, da formação e do ensino à luta dos trabalhadores. Tal luta deveria visar tanto à emancipação cultural quanto ao aumento da produção de alimentos. Com base nessa premissa, ele mostra, por meio de exemplos extraídos da experiência do trabalho desta ou daquela organização da juventude, como deveria acontecer essa educação. Primeiramente, a necessidade de fazer com que cada analfabeto da Rússia soviética lesse e escrevesse, já que, em um país analfabeto, de acordo com ele, seria impossível edificar o socialismo. A tarefa de transformar a Rússia de um país ignorante e analfabeto em um país instruído não se concretizaria rapidamente e exigia que toda a jovem geração pusesse, ela mesma, mãos à obra, indo para o campo para liquidar o analfabetismo e considerar essa tarefa como sua causa.

Sobre o enorme desafio e as dificuldades de toda ordem, apesar de a luta contra o analfabetismo ter se ressentido da fome de 1921, Lênin repetia que era um dever imediato erradicá-lo, especialmente na população com até 35 anos de idade, quando comemorassem o décimo aniversário da revolução.

Além do exemplo da luta contra o analfabetismo, Lênin menciona o trabalho nas hortas suburbanas. "O povo passa fome, há fome nas fábricas. Para nos livrarmos da fome é preciso desenvolver as hortas, mas a agricultura continua a fazer-se à antiga" (Lênin, 1980c, p. 396). Por isso, os jovens deveriam consagrar todas suas horas livres a melhorar as hortas, ou a organizar em qualquer fábrica a instrução da juventude. Além disso, era indispensável que unissem sua formação, seu ensino e sua educação ao trabalho dos operários e dos camponeses, que não se fechassem em suas escolas nem se limitassem a ler livros e brochuras marxistas. Não se fechar em suas escolas significava unir o estudo ao trabalho prático de construção da sociedade socialista (aspecto do discurso ligado ao como aprender). Não se limitar a ler livros e brochuras marxistas significava ampliar seus conhecimentos, estudando também a "ciência burguesa" (aspecto do discurso ligado a o que aprender). Lênin conclui lembrando que, na sociedade capitalista, cada um trabalhava só para si, não se preocupando se havia velhos ou doentes, "ou se todos os trabalhos da casa recaíam sobre os ombros da mulher, que se encontrava, por isso, oprimida e escravizada". E pergunta: "Quem tem o dever de lutar contra isso?" (idem, ibidem).

Com seu habitual otimismo na revolução, Lênin repetia que a tarefa não seria nem fácil nem rápida. No entanto, teria de ser iniciada. Em 1921, em outro 
discurso, voltou ao ponto: "Se eu digo que são necessárias gerações, isto não significa que sejam necessários séculos" (Lênin, 1980a, p. 476). De fato, às vésperas da hecatombe de 1939, a Rússia estava alfabetizada e eletrificada.

\section{CONCLUSÃO}

O estudo que realizamos sobre os primeiros tempos da educação soviética mostrou que as contradições ideológicas e políticas existentes entre os objetivos societários preconizados pelo liberalismo e pelo marxismo não se aplicam mecanicamente aos pressupostos teórico-metodológicos relativos à educação das crianças dos primeiros anos escolares. Nessa questão, como vimos, os bolcheviques reconheceram que Dewey estava certo ao defender o ativismo pedagógico para as crianças da primeira infância. Isso porque, para ambas as posições ideológicas antagônicas - liberalismo burguês e bolchevismo -, o ativismo pedagógico fundamentado na experiência concreta vivida pelas crianças possibilitava, do ponto de vista do sistema escolar moderno, os pressupostos da criatividade, autonomia, liberdade inventiva e, consequentemente, da embrionária relação necessária para a formação baseada nos conhecimentos de cultura geral, educação tecnológica e ginástica, isto é, o ponto de partida para a formação do homem completo, tal como propugnou Marx. Essa conclusão decorre principalmente das obras de Lounatcharski, embora, como demonstramos, Lênin e Krupskaya também compartilhassem da mesma posição política em relação ao ativismo pedagógico proposto por Dewey.

No caso de Lênin, considerando que seus discursos e artigos tiveram como alvo a juventude, esse aspecto é menos realçado do que a crítica à "velha escola", da qual rejeita seu método autoritário, o caráter excludente e a aprendizagem de cor. Todavia, rejeita descartar os conhecimentos historicamente acumulados pela humanidade e insiste na urgência de se dominar a ciência moderna. Além disso, coloca acento no aspecto político da educação. Quanto a Krupskaya, as referências a esses aspectos são mais escassas. Se a menção ao ativismo pedagógico aparece nas obras que aqui citamos, a tendência é a de sua diminuição na década seguinte. Para nós, a razão disso pode ser tributada, em parte, ao contexto histórico da vida dos três. Lênin morreu em 1924; Lounatcharski, em 1933; ela, em 1939. Por ter vivido até o final da década de 1930, Krupskaya distinguiu-se dos dois pela atuação mais prolongada no governo chefiado por Stalin (1879-1953). Em seus artigos de 1935 e 1937, por exemplo, os aspectos doutrinários e de controle ideológico sobre a educação são nítidos. Krupskaya dirigiu o Comitê de Educação Extraescolar, ao qual estavam subordinadas as organizações juvenis denominadas Pioneiros, e por meio delas fica explícita a intenção de controlar ideologicamente o aparelho escolar.

Ao estabelecermos tal distinção na atuação de Krupskaya, não queremos dizer, contudo, que elementos de controle já não estivessem presentes em Lênin e Lounatcharski. Até porque não se pode desvincular o fato de a revolução ter obtido sucesso na implementação de suas tarefas educacionais às tomadas de decisões políticas centralizadas pela direção partidária bolchevique. Tal prática remontava a 1903, quando o Partido Operário Social-Democrático Russo (POSDR), o partido dos marxistas, sofreu uma cisão entre "bolcheviques" (que em russo significa maioria), 
liderados por Lênin, e "mencheviques" (minoria). Segundo Lênin, só um partido fortemente organizado e centralizado poderia liderar uma revolução socialista na Rússia. Sua tese venceu e, a partir daí, o partido inscreveu em sua nomenclatura o termo "bolchevique". Ocorre, porém, que a tática necessária para o partido liderar a revolução foi, depois, transposta para sua relação com a sociedade soviética. Ou seja, o centralismo, que era um princípio interno ao partido, aceito e praticado pelos seus membros, passou a ser imposto do partido para o conjunto da sociedade como uma medida para consolidar o processo revolucionário.

A propósito, Hobsbawm (1995, p. 71) sustenta que, ante todas as vicissitudes, a revolução sobreviveu devido a três grandes razões. A primeira foi exatamente porque possuía um instrumento de poder único, praticamente construtor do Estado, no centralizado e disciplinado Partido Comunista; a segunda razão foi o fato de o governo bolchevique ser o único capaz de manter a Rússia integral como Estado; e a terceira consistia em que só a revolução permitiu ao campesinato tomar a terra, o que deu aos bolcheviques uma vantagem decisiva na Guerra Civil de 1918-1920.

Retomando a questão da educação no primeiro período revolucionário na Rússia Soviética, podemos concluir que, apesar do contexto histórico desfavorável ao processo de consolidação do poder bolchevique, ela foi caracterizada pelo forte entusiasmo construtivo e a vontade de profunda renovação das instituições. Nesse período, houve uma coabitação de aspectos do ativismo pedagógico com os pressupostos marxistas de educação, principalmente no que diz respeito à proposição da escola única, fundada no princípio pedagógico que combinava educação intelectual, física e tecnológica.

Mas a escola instituída pelos bolcheviques não se caracterizou apenas pela combinação entre o ativismo pedagógico e os fundamentos da concepção marxista de educação. Ela estendeu-se a todas as crianças e representou também a superação da velha escola, particularmente quando aboliu seu conteúdo religioso, nacionalista e o método de ensino baseado na pura memorização dos conhecimentos.

Contudo, a partir de 1930, com o recrudescimento político imposto por Stalin, o ativismo pedagógico foi condenado, e o trabalho nas escolas, limitado. De acordo com Cambi, foi necessário nesse contexto um conhecimento mais sistemático das ciências, o que levou "a uma reorganização da escola segundo princípios mais tradicionais (divisões em classes, retomadas das 'aulas', de horários e programas, uso de manuais, notas e disciplinas) e a um repúdio radical de toda forma de ativismo" (Cambi, 1999, p. 559).

Ainda segundo Cambi, nasceu então uma "pedagogia sem criança”, embora no início da década de 1930 tenha havido forte expansão da escolaridade, melhoramento das estruturas da escola soviética e afirmação de vozes pedagógicas originais, destacando-se Anton Makarenko (1888-1939). Além disso, apesar das tendências totalitárias, foi possível manter uma escola de cultura, e não apenas de ideologia, embora seu traço de diversidade tenha declinado, revertendo a tendência observada por Dewey, em 1928, segundo a qual a educação soviética não havia cometido o erro de confundir "unidade da educação com uniformidade", ${ }^{6}$ e

6 Além disso, Dewey (1929, p. 93) acrescenta que a centralização limitava-se ao objetivo último da educação, enquanto "no detalhe", a diversificação era permitida. 
contrariando o que escrevera Lounatcharski em 1927: "A riqueza cultural de uma sociedade é determinada pela unidade na diversidade. Pobre é a sociedade em que toda a gente se parece com tijolos" (Lounatcharski, 1988f, p. 187).

No entanto, como a educação do período stalinista não se incluía em nossos propósitos, fizemos essa breve referência apenas para indicar a hipótese de os métodos ativos praticados na década de 1920 terem sido abandonados em razão da mudança política operada pelo Estado soviético. Quanto ao nosso objetivo, esperamos ter demonstrado que era fértil a pista de Mario Alighiero Manacorda.

\section{REFERÊNCIAS}

Bittar, M.; Ferreira Jr., A. A educação na Rússia de Lênin. Revista HISTEDBR On-line, Campinas: UNICAMP, número especial, p. 377-396, abr. 2011.

Cамвi, F. História da pedagogia. Tradução de Álvaro Lorencini. São Paulo: Editora da UNESP, 1999.

Chesnais, J.-C. A vingança do terceiro mundo. Tradução de A. Bastos. Rio de Janeiro: Espaço e Tempo, 1989.

Dewey, J. Impressions of Soviet Russia and the Revolutionary World. New York: New Republic, 1929.

. A filosofia em reconstrução. Tradução de Eugênio Marcondes Rocha. São Paulo: Companhia Editora Nacional, 1958.

Experiência e educação. São Paulo: Companhia Editora Nacional, 1974.

Vida e educação. Tradução de Anísio Teixeira. São Paulo: Abril Cultural, 1980. p. 107-191.

Hoвsbawm, E. Era dos extremos: o breve século XX (1914-1991). Tradução de Marcos Santarrita. São Paulo: Companhia das Letras, 1995.

Korneychiк, N. D. Nadezja Konstantinovna Krupskaya as historian and theoretician of pedagogy. Soviet Education, New York: International Arts and Sciences Press, v. 1, n. 1-12, p. 28-34, Nov./Oct. 1958/1959.

Krupskaya, N. K. Selected Pedagogical Works. Moscow: Academy of Pedagogic Science of the RSFSR, 1957.

El movimiento de pioneiros como problema pedagogico. In: Acerca

de la educacion comunista: articulos y discursos. Traducido del ruso por V. Sanchez Esteban. Moscú: Ediciones en Lenguas Extranjeras, s.d.a, p. 88-92.

.Hay que preocuparse del desarrolo multiple de los niños. In: Acerca

de la educacion comunista: articulos y discursos. Traducido del ruso por V. Sanchez Esteban. Moscú: Ediciones en Lenguas Extranjeras, s.d.b, p. 93-97.

LÊNIN, V. I. As tarefas imediatas do poder soviético. In: Obras escolbidas. São Paulo: Editora Alfa-Omega, 1980a. t. 2, p. 557-587.

Conversa com o correspondente do jornal americano The World, Lincoln Eire. In: Obras escolhidas. São Paulo: Editora Alfa-Omega, 1980b. t. 3, p. 253-257. 
As tarefas das uniões da juventude. In: Obras escolbidas. São Paulo: Editora Alfa-Omega, 1980c. t. 3, p. 386-397.

Lounatchars Ki, A. O que é a instrução? In: Sobre a instrução e a educação. Tradução de Felipe Guerra. Moscou: Edições Progresso, 1988a. p. 42-55.

. De que escola precisa um Estado proletário? In: Sobre a instrução e a educação. Tradução de Felipe Guerra. Moscou: Edições Progresso, 1988b. p. 111-133. Da escola de classe. In: Sobre a instrução e a educação. Tradução de Felipe Guerra. Moscou: Edições Progresso, 1988c. p. 77-102.

A filosofia da escola e a revolução. In: Sobre a instrução e a educação. Tradução de Felipe Guerra. Moscou: Edições Progresso, 1988d. p. 134-156.

Tarefas da instrução pública no sistema da edificação soviética. In:

Sobre a instrução e a educação. Tradução de Felipe Guerra. Moscou: Edições Progresso, 1988e. p. 157-180.

A arte verbal na escola. In: Sobre a instrução e a educação. Tradução de Felipe Guerra. Moscou: Edições Progresso, 1988f. p. 181-188.

. Premissas sociológicas da pedagogia soviética. In: Sobre a instrução e a educação. Tradução de Felipe Guerra. Moscou: Edições Progresso, 1988g. p. 189-198.

A formação de um homem novo. In: Sobre a instrução e a educação. Tradução de Felipe Guerra. Moscou: Edições Progresso, 1988h. p. 199-221.

Luzuriaga, L. História da educação e da pedagogia. Tradução de Luiz Damasco Penna. São Paulo: Editora Nacional, 1980.

Malkova, Z. Education: the Soviet Union today and tomorrow. Moscow: Novosti Press Agency Publishing House, 1985.

Manacorda, M. A. História da educação: da Antiguidade aos nossos dias. Tradução de Gaetano Lo Mônaco. São Paulo: Cortez; Autores Associados, 1989.

Mariconda, P. R. Dewey (1859-1951): vida e obra. In: Dewey, J. Experiência e natureza. Lógica: a teoria da investigação. A arte como experiência. Vida e educação. Teoria da vida moral. Tradução de Murilo Otávio Rodrigues Paes Leme et al. São Paulo: Abril Cultural, 1980.

Prozorov, G. S. Views of Nadezja Konstantinovna Kruspskaya on didacties. Soviet Education, New York: International Arts and Sciences Press, v. 1, n. 1-12, p. 35-42, Nov./Oct. 1958/1959.

Teixeira, A. A pedagogia de Dewey. In: Dewey, J. Vida e educação. Tradução de Anísio Teixeira. São Paulo: Abril Cultural, 1980. p. 113-135.

\section{SOBRE OS AUTORES}

Marisa Bittar é doutora em história social pela Universidade de São Paulo (USP). Professora titular da Universidade Federal de São Carlos (UFSCar). E-mail:bittar@ufscar.br 
Marisa Bittar e Amarilio Ferreira Jr.

Amarilio Ferreira Jr. é doutor em história social pela Universidade de São Paulo (USP). Professor titular da Universidade Federal de São Carlos (UFSCar). E-mail:ferreira@ufscar.br

Recebido em maio de 2013

Aprovado em março de 2014 